\title{
Resveratrol Attenuates High Glucose-Induced Vascular Endothelial Cell Injury by Activating the E2F3 Pathway
}

\author{
Xiaolian Ding, ${ }^{1}$ Wei Yao, ${ }^{2}$ Jie $\mathrm{Zhu}^{2}$ Kaida $\mathrm{Mu}^{2}$ Jing Zhang $\mathbb{D}^{2},{ }^{2}$ and Jin-an Zhang $\mathbb{D}^{2}$ \\ ${ }^{1}$ Department of Nephrology and Endocrinology, Weinan Central Hospital of Weinan, Shaanxi Province, China 714000 \\ ${ }^{2}$ Department of Endocrinology, Shanghai University of Medicine \& Health Sciences, Affiliated Zhoupu Hospital, No. 1500 \\ Zhouyuan Road, Pudong New District, Shanghai, China 201318
}

Correspondence should be addressed to Jing Zhang; zhangjingzhoupu@163.com and Jin-an Zhang; zhangjinan@hotmail.com

Received 30 November 2019; Revised 21 March 2020; Accepted 10 April 2020; Published 28 April 2020

Academic Editor: Konstantinos Kantartzis

Copyright (c) 2020 Xiaolian Ding et al. This is an open access article distributed under the Creative Commons Attribution License, which permits unrestricted use, distribution, and reproduction in any medium, provided the original work is properly cited.

Type 2 diabetes mellitus (T2DM) is the most common metabolic disease. High glucose-induced macrovascular disease and microangiopathy are major complications of diabetes. E2F3, a member of the E2F transcription factor family, is closely related to cardiovascular diseases. Resveratrol, a nonflavonoid polyphenolic compound widely found in plants, has been shown to have cardiovascular protection. However, there are few studies on whether resveratrol can effectively treat diabetic angiopathy, and the specific mechanism involved needs further study. This study investigated whether E2F3 transcription factors are involved in the process of vascular endothelial injury induced by high glucose and observed its effects on the proliferation of vascular endothelial cells. Then, it analyzed whether resveratrol can inhibit high glucose-induced vascular endothelial cell injury by regulating the E2F3 pathway. We demonstrated that the expression level of the E2F3 transcription factor was significantly inhibited in high glucose state. Resveratrol inhibited high glucose-induced vascular endothelial cell injury by upregulating the E2F3 pathway. High glucose can induce vascular endothelial injury by inhibiting E2F3 gene expression, while resveratrol can inhibit high glucose-induced vascular endothelial injury by activating the E2F3 pathway.

\section{Introduction}

Type 2 diabetes mellitus (T2DM), the most common metabolic disease, is mainly caused by islet $\beta$-cell dysfunction and insulin resistance [1]. With the improvement of living standards and lifestyle changes, the prevalence of T2DM has been increasing year by year and has become a worldwide epidemic disease, and there are currently more than 400 million T2DM patients worldwide [1]. In addition, T2DM occurs in a younger population, and more and more adolescents are beginning to suffer from T2DM [2]. Macrovascular diseases and microvascular diseases are the main complications of diabetes, and the primary disabling and lethal factors have become the core problem of diabetes treatment. Although the current hypoglycemic drugs and methods for diabetes have made great progress, these treatments are not effective in reducing the risk of diabetic vascular complications [3]. In addition to active hypoglycemic and lipid-lowering and blood pressure control, there is currently no drug that can effectively prevent or treat diabetic complications.

It has been clarified that vascular endothelial cell injury caused by high glucose is the initiating factor and the main pathogenesis of diabetic vascular disease and plays a key role in the occurrence and development of diabetic vascular complications. Excessive apoptosis and dysfunction of vascular endothelial cells caused by high glucose can increase the permeability of endothelium, thereby promoting the invasion of blood lipid components and immune cells such as monocytes into the vascular endothelium, and gradually aggravating diabetes. At present, it has been found that hyperglycemia can damage the function of vascular endothelial cells through various mechanisms, such as inflammation and oxidative stress; however, the specific molecular mechanism remains to be further studied [1]. In-depth study of the pathogenesis of vascular endothelial dysfunction induced by high glucose can help to explain the mechanism of diabetic vascular 
disease, and it has great clinical significance for the prevention and treatment of diabetic vascular complications.

The E2F family is a group of transcription factors closely related to cell proliferation and differentiation. It plays a key role in the regulation of cell cycle and cell proliferation and is composed of eight different members (E2F1-E2F8) [4-7]. Although E2F transcription factors are mainly involved in cell cycle regulation, each member has diverse and complex biological functions and also functions to regulate immune response and substance metabolism $[8,9]$. As a member of the E2F transcription factor family, E2F3 plays an important role in regulating the cell cycle [10]. Several studies have also shown that E2F3 is closely related to cardiovascular diseases [11-13]. E2F3 knockout mice have dysplasia or congestive heart failure, suggesting that E2F3 plays an important role in the development of the cardiovascular system or in maintaining normal functions $[14,15]$. In addition, E2F3 can also regulate islet $\beta$ cell proliferation and stem cell differentiation $[16,17]$, indicating that E2F3 can play different regulatory functions by targeting different genes in different tissue cells [10]. At present, the role and mechanism of E2F3 in regulating vascular endothelial cell function is still unclear, and its role in the induction of vascular endothelial injury by high glucose remains unclear. Resveratrol is a nonflavonoid polyphenolic compound widely found in wine and various traditional Chinese medicines. It has significant antioxidation, anti-inflammatory, and antiaging effects. Many studies have shown that resveratrol has cardiovascular protection [18, 19]. Resveratrol can protect the cardiovascular system by improving lipid metabolism, acting against oxidation, scavenging free radicals, and inhibiting various inflammatory factors $[18,19]$. However, there are few studies on whether resveratrol can effectively treat diabetic angiopathy, and the specific mechanism involved needs further study. In summary, in order to further study the pathogenesis of diabetic angiopathy, we propose the following hypotheses: E2F3 transcription factor plays an important role in regulating vascular endothelial cell function. High glucose can induce vascular endothelial injury by inhibiting the E2F3 pathway, and resveratrol can inhibit high glucose-induced vascular endothelial injury by activating the E2F3 pathway.

\section{Materials and Methods}

2.1. Construction of High Glucose-Induced HUVEC Injury Model. Primary human umbilical vein endothelial cells (HUVECs) were purchased (ATCC) and cultured in ECM cell culture medium at $37^{\circ} \mathrm{C}$ under $5 \% \mathrm{CO}_{2}$. The medium was changed every other day, and cells of passage 3-5 were used for the experiment. When HUVECs were grown to $70-80 \%$ density, the cultured cells were randomly divided into normal control group $(5.5 \mathrm{mmol} / \mathrm{L}$ glucose $)$, highglucose group $(25.6 \mathrm{mmol} / \mathrm{L}$ glucose $)$, and high-glucose group ( $33.3 \mathrm{mmol} / \mathrm{L}$ glucose). The morphological changes of cells were observed by light microscopy at $0 \mathrm{~h}, 24 \mathrm{~h}$, and $48 \mathrm{~h}$. The proliferation of HUVEC cells was detected by CCK-8 method. Flow cytometry Annexin V was used to detect apoptosis levels.
2.2. Targeted Regulation of E2F3 Expression Levels. HUVECs were randomly divided into normal control group (5.5 mmol/L glucose), high-glucose control group 2 (33.3 mmol/L glucose), high-glucose/E2F3 overexpression plasmid (33.3 mmol/L glucose + E2F3 overexpression plasmid transfection), and high-glucose/E2F3 siRNA plasmid group (33.3 mmol/L glucose + E2F3 siRNA plasmid transfection) when growing to $70-80 \%$ confluence. The E2F3 expression intervention group was preincubated with the corresponding E2F3 overexpression plasmid or E2F3 siRNA plasmid for $24 \mathrm{~h}$, and the other groups were cultured under normal conditions for $24 \mathrm{~h}$ under the same conditions. The target sequence of the E2F3 gene for the construction of lentivirus and siRNA was $5^{\prime}$-UAACCUUUGAUUCUCUGAA UCCUCG-3'.

2.3. Resveratrol Intervention. The cells were randomly divided into blank control group, resveratrol low-concentration intervention group $(10 \mu \mathrm{mol} / \mathrm{L}$ resveratrol $)$, and resveratrol medium-concentration intervention group $(33 \mu \mathrm{mol} / \mathrm{L}$ resveratrol), resveratrol high-concentration intervention group $(100 \mu \mathrm{mol} / \mathrm{L}$ resveratrol) and resveratrol high-concentration + E2F3 siRNA plasmid intervention group $(100 \mu \mathrm{mol} / \mathrm{L}$ resveratrol + E2F3 siRNA plasmid transfection). Cells were incubated for $24 \mathrm{~h}$ using the corresponding preformulated media as described above. Then the original medium was aspirated and high-glucose medium (33.3 mmol/L glucose) was added. The morphology and proliferation of HUVEC cells were detected by high-glucose stimulation of HUVEC cells for $48 \mathrm{~h}$.

2.4. Real-Time PCR. RNA was extracted using the RNeasy kit (Qiagen), and then complementary DNA (cDNA) was synthesized from $1 \mathrm{mg}$ of RNA. qRT-PCR was performed in triplicate using SYBR Green PCR Master Mix with a total reaction volume of $15 \mu \mathrm{L}$. The reaction was carried out using an Applied Biosystems 7500 real-time PCR system. The PCR procedure was as follows: one cycle was performed at $95^{\circ} \mathrm{C}$ for 30 seconds, followed by 40 two-step cycles of 5 seconds at $95^{\circ} \mathrm{C}$, and 34 seconds at $63^{\circ} \mathrm{C}$. E2F3 upstream primer sequence: $5^{\prime}$-ACGTCTCTTGGTCTGCTCAC-3', downstream primer sequence: $5^{\prime}$-TCTTAATGAGGTGGATGCCT-3'.

2.5. CCK-8. Cell suspension of $100 \mu \mathrm{L}$ was placed in a $96-$ well plate. The plate was preincubated in an incubator for $24 \mathrm{~h}$ $\left(37^{\circ} \mathrm{C}, 5 \% \mathrm{CO}_{2}\right)$. We added $10 \mu \mathrm{L}$ of different concentrations of the test substance to the plate and incubated the plate in the incubator for a suitable period of time (for example, 6 , 12,24 , or 48 hours). Then, $10 \mu \mathrm{L}$ of CCK8 solution was added to each well (be careful not to create bubbles in the wells that will affect the OD reading). The plate was incubated in an incubator for 1-4 hours, and then the absorbance at $450 \mathrm{~nm}$ was measured with a microplate reader.

2.6. Flow Cytometry for Apoptosis Assay. The normal cultured and induced apoptosis cells $(0.5 \sim 1 \times 106)$ were washed twice with PBS, $100 \mu \mathrm{L}$ of staining buffer and FITC-labeled Annexin V $(20 \mu \mathrm{g} / \mathrm{mL})$ of $10 \mu \mathrm{L}$ were added, and the cells were protected from light for $30 \mathrm{~min}$ at room temperature. 
We added PI $(50 \mu \mathrm{g} / \mathrm{mL}) 5 \mu \mathrm{L}$, avoiding the light reaction for $5 \mathrm{~min}$, added $400 \mu \mathrm{L}$ of binding buffer, and immediately used FACS for quantitative detection by flow cytometry (not more than $1 \mathrm{~h}$ ), without adding Annexin V-FITC and one tube of PI served as a negative control.

2.7. Statistical Analysis. Data are expressed as mean \pm SD. A paired $t$ test was used to compare E2F3 gene expression levels among the groups. $P<0.05$ was considered statistically significant. Statistical analysis was performed using SPSS Statistics version 20 (IBM, Chicago, IL, USA). Flow cytometry data was analyzed using the FlowJo software v10.0 (Tree Star Inc, Ashland, OR).

\section{Results}

3.1. Changes of Cell Morphology and Proliferation Activity in High Glucose-Induced HUVEC Injury and Resveratrol Treatment. We examined the cell morphology and proliferation at different sugar concentrations and found that the cell morphology was significantly impaired under high-glucose conditions (Figure 1). The CCK8 experiment showed that high glucose inhibited cell proliferation (Figure 2). When the glucose concentration was $33.3 \mathrm{mmol} / \mathrm{L}$, the cell proliferation curve was significantly lower than that of $5.5 \mathrm{mmol} / \mathrm{L}$, which indicated that high-sugar concentration would inhibit the cells' proliferation activity $(P=0.02$ at $48 \mathrm{~h})$. But when $100 \mu \mathrm{mol} / \mathrm{L}$ of resveratrol was added to the $33.3 \mathrm{mmol} / \mathrm{L}$ glucose medium, the cells' proliferation activity was restored again $(P=0.008$ in $48 \mathrm{~h})$. With a glucose concentration of $33.3 \mathrm{mmol} / \mathrm{L}$ and $100 \mu \mathrm{mol} / \mathrm{L}$ resveratrol and transfection with E2F3 overexpression lentivirus, the cell's proliferation curve was the most significantly high, which indicated that the cells grew best. In contrast, when the cells were transfected with E2F3 siRNA, their proliferation curve was the lowest, indicating that the cells had the worst growth and suffered significant damage $(P=0.001$ at $48 \mathrm{~h})$.

3.2. Changes of E2F3 Expression Level in High GlucoseInduced HUVEC Injury and Resveratrol Treatment. Through real-time PCR experiments, we found that there was no significant difference in E2F3 gene expression between $5.5 \mathrm{mmol} / \mathrm{L}$ glucose and $25.6 \mathrm{mmol} / \mathrm{L}$ glucose $(P<0.05)$. But when the sugar concentration was as high as $33.3 \mathrm{mmol} / \mathrm{L}, \mathrm{E} 2 \mathrm{~F} 3$ gene expression decreased significantly $(P=0.01)$. When the cells were transfected with E2F3 overexpressing lentivirus at a sugar concentration of $33.3 \mathrm{mmol} / \mathrm{L}$, E2F3 gene expression was significantly increased $(P=0.0005)$. In contrast, when E2F3 siRNA was used, the E2F3 gene expression was significantly suppressed $(P=0.0004)$. This indicated that our plasmid transfection experiments and lentiviral transfection experiments were very successful. We further found that when resveratrol was used at high sugar levels, the expression of E2F3 increased gradually with the concentration of resveratrol, especially at $100 \mu \mathrm{mol} / \mathrm{L}$ of resveratrol $(P=0.001)$. At high sugar concentrations, when high concentrations of resveratrol and E2F3 siRNA plasmid were used simultaneously, the expression of E2F3 was significantly suppressed. With high concentrations of resveratrol and
E2F3 overexpressing lentivirus, the expression of E2F3 was the highest among all the groups. The difference between these two groups was very significant $(P<0.0001)$ (Figure 3$)$.

3.3. Changes of Apoptosis Rate in High Glucose-Induced HUVEC Injury and Resveratrol Treatment. Flow cytometry experiments showed that the proportion of apoptosis increased under high-glucose conditions (Figure 4). When the glucose concentration was normal, the cells had an apoptosis rate of $3.6 \pm 0.32 \%$, and when the glucose concentration was $33.3 \mathrm{mmol} / \mathrm{L}$, the apoptosis rate of the cells increased significantly, reaching $5.6 \pm 0.43 \%$ (mean $\pm \mathrm{SD})(P=0.001)$. Importantly, we discovered that when $100 \mu \mathrm{mol} / \mathrm{L}$ of resveratrol was added, compared with no resveratrol, the cell apoptosis rate was significantly reduced to be only $4.65 \pm$ $0.32 \%(P=0.002)$. When the E2F3 gene was overexpressed, the apoptosis rate was even lower, only $3.47 \pm 0.34 \%$ $(P=0.002)$. Then we knocked down the E2F3 gene using siRNA and found that the protective effect of resveratrol was significantly weakened, and the apoptosis rate increased to $5.03 \pm 0.21 \%(P=0.006)$ (Figure 4$)$.

\section{Discussion}

At present, the role and mechanism of the E2F-like transcription factor pathway in high glucose-induced vascular endothelial dysfunction remains unclear. Our study found for the first time that E2F3 was inhibited in high-glucose states, suggesting that the E2F3 transcription factor pathway may play an important role in diabetic angiopathy. Resveratrol, a widely versatile drug, was first discovered to protect vascular endothelial cells under high-glucose damage by activating the E2F3 pathway. This demonstrates the potential use of resveratrol in the treatment of diabetes.

The E2F family is a group of transcription factors closely related to cell proliferation and differentiation. It plays a key role in the regulation of cell cycle and cell proliferation and is composed of eight different members (E2F1-E2F8). [4-7]. Although E2F transcription factors are mainly involved in cell cycle regulation, each member has diverse and complex biological functions, and also functions to regulate immune response and substance metabolism $[8,9]$. Many studies have demonstrated that E2F-like transcription factors play important regulatory roles in the cardiovascular system, and their dysfunction may be associated with multiple cardiovascular diseases [11, 12, 20-27]. In addition, different E2F transcription factors have significant effects on the cardiovascular system, such as different regulation of proliferation or apoptosis of vascular smooth muscle cells or cardiomyocytes [13, 2830]. E2F3 mainly consists of two subtypes, E2F3a and E2F3b. They are encoded by a single locus through the use of different promoters and $5^{\prime}$ coding exons. E2F3a has been extensively characterized and is classified as a member of the activated E2F group, which includes E2F1, E2F2, and E2F3a. E2F1 is the first E2F transcription factor discovered, and there are many studies on its role in cardiovascular diseases [22, 27, 31, 32]. E2F1 is closely related to apoptosis of vascular endothelial cells, and overexpression of E2F1 can inhibit the apoptosis-promoting effect of tumor necrosis 


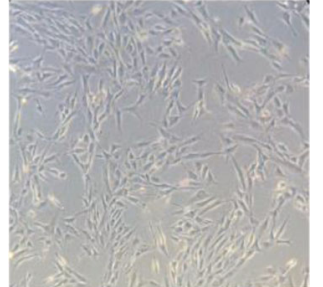

(a)

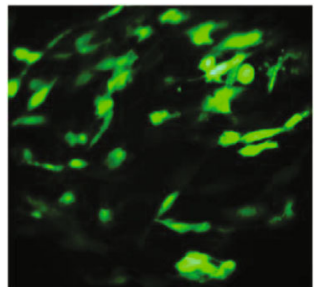

(d)

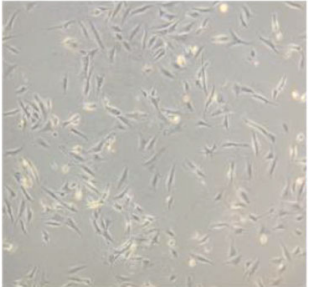

(b)

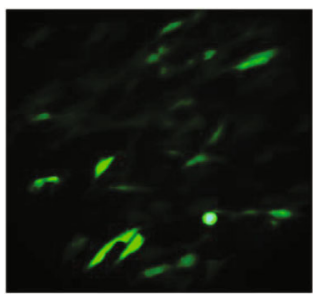

(e)

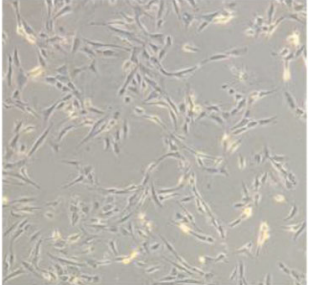

(c)

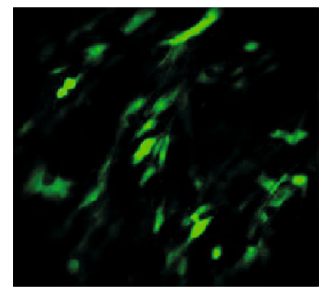

(f)

FIGURE 1: The cell morphology was significantly impaired under high glucose and partly restored by resveratrol. (a) The cell morphology in normal glucose. (b) The cell morphology in $33.3 \mathrm{mmol} / \mathrm{L}$ glucose. (c) The cell morphology in $33.3 \mathrm{mmol} / \mathrm{L}$ glucose and $100 \mu \mathrm{mol} / \mathrm{L}$ resveratrol. (d) Transferred to E2F3 overexpressing lentivirus at normal sugar concentration. (e) Transferred to E2F3 overexpressing lentivirus at $33.3 \mathrm{mmol} / \mathrm{L}$ glucose sugar concentration. (f) Transferred to E2F3 overexpressing lentivirus at $33.3 \mathrm{mmol} / \mathrm{L}$ glucose sugar concentration and $100 \mu \mathrm{mol} / \mathrm{L}$ resveratrol.

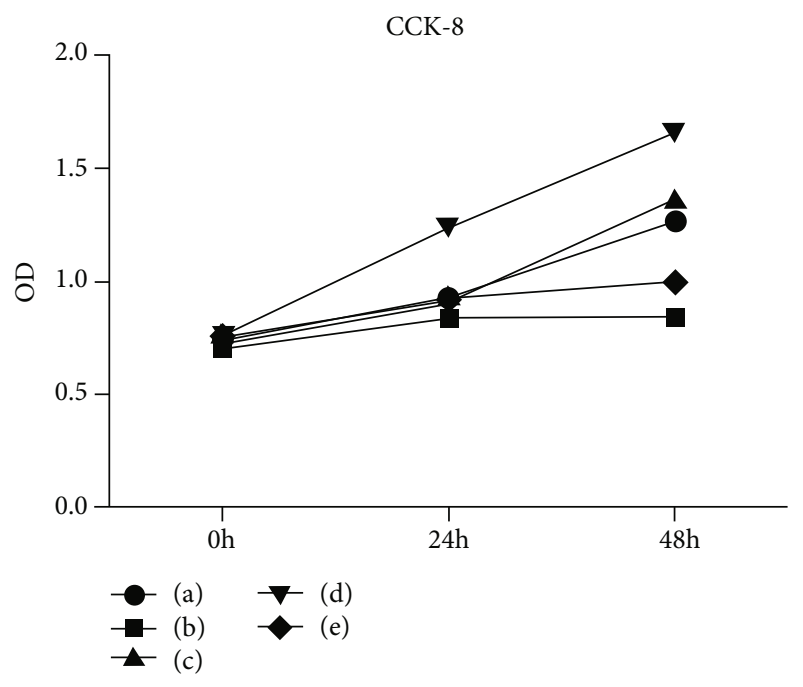

FIGURE 2: Cell proliferation activity decreased after high-glucose damage, but resveratrol could partially restore it. (a) Cell proliferation activity in normal glucose level. (b) Cell proliferation activity in $33.3 \mathrm{mmol} / \mathrm{L}$ glucose. (c) Cell proliferation activity in $33.3 \mathrm{mmol} / \mathrm{L}$ glucose and $100 \mu \mathrm{mol} / \mathrm{L}$ resveratrol. (d) Transferred to $\mathrm{E} 2 \mathrm{~F} 3$ overexpressing lentivirus at $33.3 \mathrm{mmol} / \mathrm{L}$ glucose and $100 \mu \mathrm{mol} / \mathrm{L}$ resveratrol. (e) Transferred to E2F3 siRNA at $33.3 \mathrm{mmol} / \mathrm{L}$ glucose sugar concentration and $100 \mu \mathrm{mol} / \mathrm{L}$ resveratrol.

factor alpha [27]. E2F1 is also associated with abnormal proliferation of vascular smooth muscle cells caused by high glucose [32]. In addition, E2F1 can affect the formation of new blood vessels and functional recovery after myocardial infarction by downregulating the expression level of VEGF molecules [22]. Similar to E2F1, E2F2 is closely related to the function of vascular endothelial cells and cardiomyocytes,

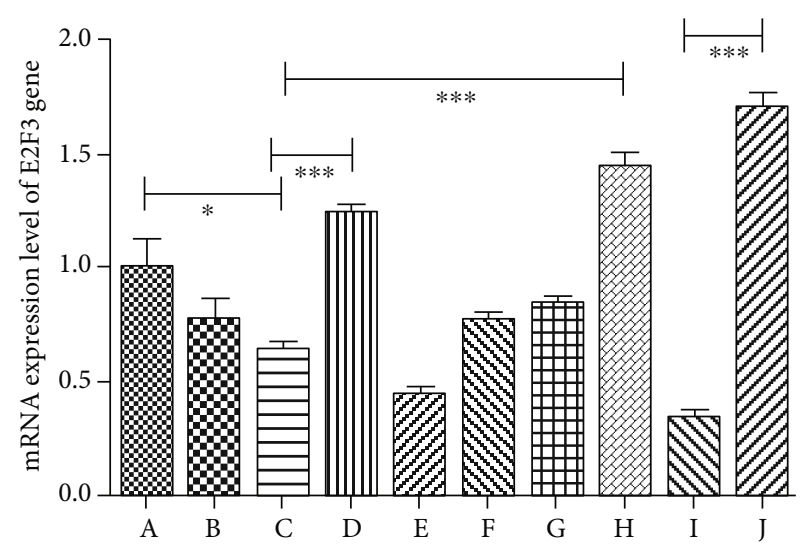

FIgURE 3: mRNA expression level of E2F3 gene. (a) $5.5 \mathrm{mmol} / \mathrm{L}$ glucose. (b) $25.6 \mathrm{mmol} / \mathrm{L}$ glucose. (c) $33.3 \mathrm{mmol} / \mathrm{L}$ glucose. (d) $33.3 \mathrm{mmol} / \mathrm{L}$ glucose $+\mathrm{E} 2 \mathrm{~F} 3$ overexpression plasmid transfection. (e) $33.3 \mathrm{mmol} / \mathrm{L}$ glucose $+\mathrm{E} 2 \mathrm{~F} 3$ siRNA plasmid transfection. (f) $33.3 \mathrm{mmol} / \mathrm{L}$ glucose $+10 \mu \mathrm{mol} / \mathrm{L}$ resveratrol. (g) $33.3 \mathrm{mmol} / \mathrm{L}$ glucose $+33 \mu \mathrm{mol} / \mathrm{L}$ resveratrol. (h) $33.3 \mathrm{mmol} / \mathrm{L}$ glucose + $100 \mu \mathrm{mol} / \mathrm{L}$ resveratrol. (i) $33.3 \mathrm{mmol} / \mathrm{L}$ glucose $+100 \mu \mathrm{mol} / \mathrm{L}$ resveratrol + E2F3 siRNA plasmid transfection. (j) $33.3 \mathrm{mmol} / \mathrm{L}$ glucose $+100 \mu \mathrm{mol} / \mathrm{L}$ resveratrol $+\mathrm{E} 2 \mathrm{~F} 3$ overexpressing lentivirus. $(* P<0.05, * * P<0.01, * * * P<0.005)$.

and its dysfunction may also be involved in the pathogenesis of various cardiovascular diseases $[13,26,30]$. Several studies have also shown that E2F3 is closely related to cardiovascular diseases [11-13]. E2F3 knockout mice have dysplasia or congestive heart failure, indicating that E2F3 plays an important role in the development of the cardiovascular system or maintenance of its normal functions $[14,15]$. In addition, E2F3 can also regulate islet $\beta$ cell proliferation and stem cell differentiation $[16,17]$. 


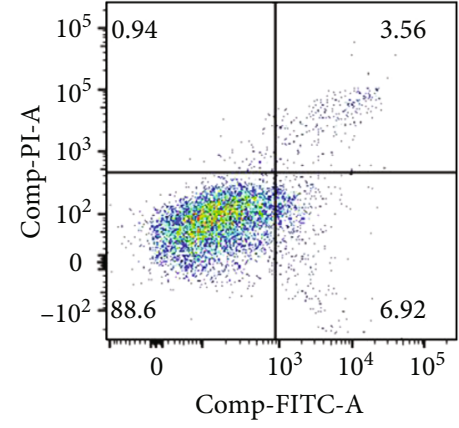

(a)

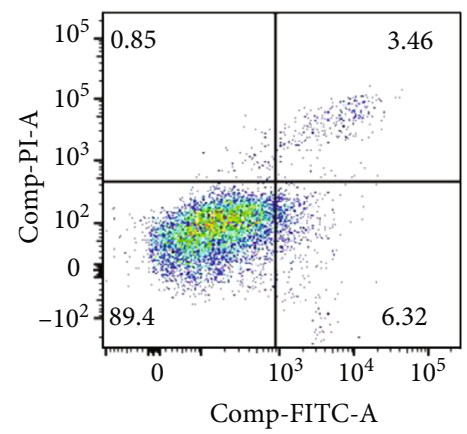

(d)

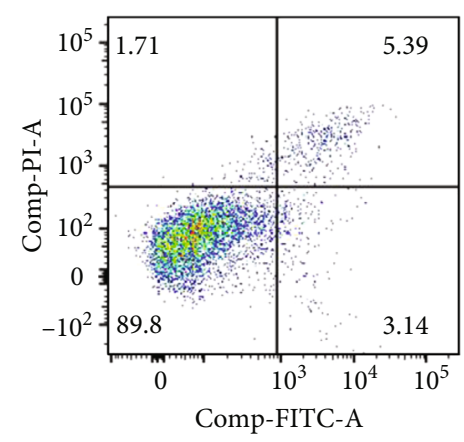

(b)

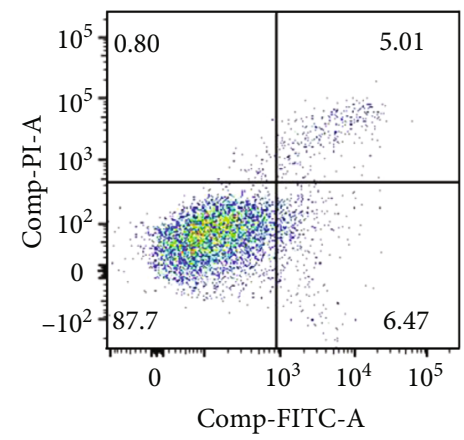

(e)

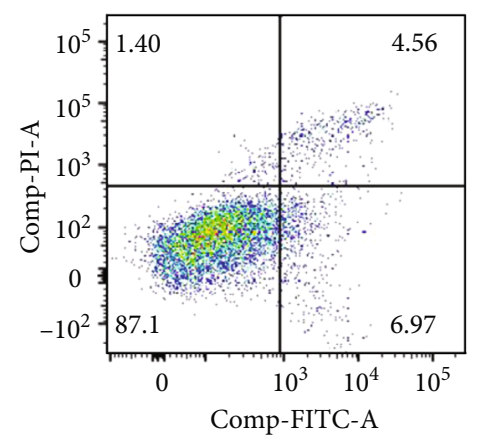

(c)

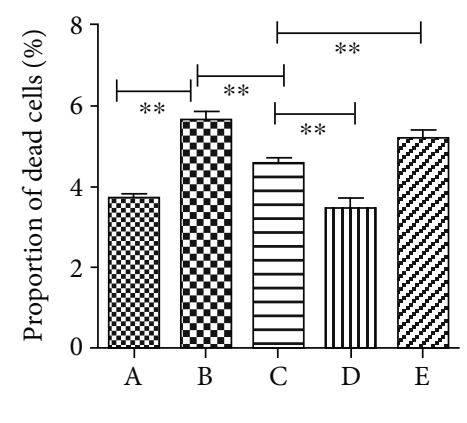

(f)

FIGURE 4: Resveratrol could reduce apoptosis induced by high glucose. (a) Apoptosis rate of cells in normal glucose. (b) Apoptosis rate of cells in $33.3 \mathrm{mmol} / \mathrm{L}$ glucose. (c) Apoptosis rate of cells in $33.3 \mathrm{mmol} / \mathrm{L}$ glucose and $100 \mu \mathrm{mol} / \mathrm{L}$ resveratrol. (d) Apoptosis rate of cells in $33.3 \mathrm{mmol} / \mathrm{L}$ glucose and $100 \mu \mathrm{mol} / \mathrm{L}$ resveratrol with E2F3 overexpressing lentivirus. (e) Apoptosis rate of cells in $33.3 \mathrm{mmol} / \mathrm{L}$ glucose and $100 \mu \mathrm{mol} / \mathrm{L}$ resveratrol with E2F3 siRNA. (f) Flow cytology apoptosis rate statistical histogram. $(* P<0.05, * * P<0.01, * * * P<0.005)$.

Resveratrol, with the chemical name of 3, 4', 5 -trihydroxystilbene, is a nonflavonoid polyphenolic compound and is produced by plants (mainly seed plants) in the face of adverse conditions such as fungal infections and ultraviolet radiation. It is essentially a plant defensin that protects plants themselves and is found in more than 70 plants, such as the grape family, the lily family, and the legume family, especially abundant in grapes [33]. With the deep research on resveratrol, it has been found to have a wide range of pharmacological effects, such as antitumor, anticardiovascular disease, anti-inflammatory, immunomodulatory, antibacterial, antiviral, antiaging, and estrogen-like activities. In addition, it can alleviate the damage of tissues and organs caused by many factors and protect liver cells $[18,19]$. In terms of the regulation of blood vessels, resveratrol has been shown to have a broad relaxing effect on blood vessels. Resveratrol inhibits contractile reactivity of isolated intact rat arteries to norepinephrine in a dose-dependent manner. In addition, resveratrol has also been found to be resistant to atherosclerosis and has a role in the prevention and treatment of coronary atherosclerotic heart disease. Resveratrol has even been found to reduce myocardial ischemiareperfusion injury $[34,35]$. However, we first found that the E2F3 gene of vascular endothelial cells was inhibited in the high-glucose state, which would lead to cell damage, and activation of the E2F3 pathway could protect vascular endothelial cells.
In fact, the study on resveratrol for diabetes has been widely studied in animal models and diabetic patients, but mainly focused on lowering blood sugar levels and insulin resistance. Scientists have demonstrated that resveratrol improves glucose homeostasis, reduces insulin resistance, protects islet beta cells, improves insulin secretion, and improves metabolic disorders $[36,37]$. The resveratrolinduced effect is closely related to the ability of the compound to increase the expression/activity of AMPK and SIRT1 in various tissues of diabetic subjects. Furthermore, it has been shown that the antioxidant and anti-inflammatory effects of resveratrol are also seen in diabetic animals. However, the effect of resveratrol on vascular endothelium in diabetes was rarely studied. Our study demonstrates for the first time that resveratrol protects vascular endothelial cells under highglucose induced-damage by activating the E2F3 pathway. This is very meaningful for expanding people's perception of the role of resveratrol.

In order to further study the pathogenesis of diabetic angiopathy, we have demonstrated through this experiment that the E2F3 transcription factor plays an important role in regulating vascular endothelial cell function. High glucose can induce vascular endothelial injury by inhibiting the E2F3 pathway, while resveratrol can inhibit high glucose-induced vascular endothelial injury by activating the E2F3 pathway. Interventional treatment mechanism of resveratrol on high glucose-induced vascular endothelial injury may also provide 
new ideas and therapeutic targets for the prevention and treatment of diabetes-related vascular lesions.

\section{Conclusions}

In conclusion, we find that high glucose can induce vascular endothelial injury by inhibiting E2F3 gene expression, while resveratrol can inhibit high glucose-induced vascular endothelial injury by activating the E2F3 pathway.

\section{Abbreviations}

T2DM: Type 2 diabetes mellitus

HUVEC: Human umbilical vein endothelial cells

cDNA: Complementary DNA.

\section{Data Availability}

The datasets used and/or analyzed during the current study are available from the corresponding author on reasonable request.

\section{Ethical Approval}

The study was approved by the Ethics Committee of Zhoupu Hospital, and written informed consent was obtained from all participants.

\section{Conflicts of Interest}

The authors declare that they have no competing interests.

\section{Authors' Contributions}

$\mathrm{J}-\mathrm{aZ}$ was responsible for the concept of the study. XLD, JZ, and J-aZ designed the study. XLD, JZ, J-aZ, WY, JZ, and $\mathrm{KDM}$ contributed to the literature search, interpretation, and writing of the manuscript.

\section{Acknowledgments}

The authors would like to acknowledge all works leading to this paper. This study was supported by the Seed Fund Program of Shanghai University of Medicine \& Health Sciences (SFP-18-21-17-003), Discipline Construction of Health and Family Planning Commission in Pudong New Area-Diabetes Mellitus (PWZzb2017-25), and The Project of Shanghai Medical Key Specialty (No. ZK2019C09).

\section{References}

[1] S. Chatterjee, K. Khunti, and M. J. Davies, "Type 2 diabetes," Lancet, vol. 389, no. 10085, pp. 2239-2251, 2017.

[2] N. Lascar, J. Brown, H. Pattison, A. H. Barnett, C. J. Bailey, and S. Bellary, "Type 2 diabetes in adolescents and young adults," The Lancet Diabetes and Endocrinology, vol. 6, no. 1, pp. 6980, 2018.

[3] R. R. Holman, H. Sourij, and R. M. Califf, "Cardiovascular outcome trials of glucose-lowering strategies in type 2 diabetesAuthors' reply," Lancet, vol. 384, no. 9948, pp. 1097-1098, 2014.
[4] J. M. Ankers, R. Awais, N. A. Jones et al., "Dynamic NF- $\kappa$ B and E2F interactions control the priority and timing of inflammatory signalling and cell proliferation," eLife, vol. 5, pp. 176189, 2016.

[5] L. M. Julian and A. Blais, "Transcriptional control of stem cell fate by E2Fs and pocket proteins," Frontiers in Genetics, vol. 6, p. 161, 2015.

[6] J. S. Kwon, N. J. Everetts, X. Wang et al., "Controlling depth of cellular quiescence by an Rb-E2F network switch," Cell Reports, vol. 20, no. 13, pp. 3223-3235, 2017.

[7] H. Liu, X. Tang, A. Srivastava et al., "Redeployment of Myc and E2f1-3 drives Rb-deficient cell cycles," Nature Cell Biology, vol. 17, no. 8, pp. 1036-1048, 2015.

[8] W. Béguelin, M. A. Rivas, M. T. Calvo Fernández et al., "EZH2 enables germinal centre formation through epigenetic silencing of CDKN1A and an Rb-E2F1 feedback loop," Nature Communications, vol. 8, no. 1, p. 877, 2017.

[9] Q. Lai, A. Giralt, C. le May et al., "E2F1 inhibits circulating cholesterol clearance by regulating Pcsk9 expression in the liver," JCI Insight, vol. 2, no. 10, 2017.

[10] L. M. Julian, Y. Liu, C. A. Pakenham et al., "Tissue-specific targeting of cell fate regulatory genes by E2f factors," Cell Death and Differentiation, vol. 23, no. 4, pp. 565-575, 2016.

[11] J. L. Major, M. Salih, and B. S. Tuana, "Interplay between the E2F pathway and $\beta$-adrenergic signaling in the pathological hypertrophic response of myocardium," Journal of Molecular and Cellular Cardiology, vol. 84, pp. 179-190, 2015.

[12] J. L. Major, M. Salih, and B. S. Tuana, "E2F6 protein levels modulate drug induced apoptosis in cardiomyocytes," Cellular Signalling, vol. 40, pp. 230-238, 2017.

[13] J. Zhou, M. Cheng, M. Wu et al., "Contrasting roles of E2F2 and E2F3 in endothelial cell growth and ischemic angiogenesis," Journal of Molecular and Cellular Cardiology, vol. 60, pp. 68-71, 2013.

[14] J. E. Cloud, C. Rogers, T. L. Reza et al., "Mutant mouse models reveal the relative roles of E2F1 and E2F3 in vivo," Molecular and Cellular Biology, vol. 22, no. 8, pp. 2663-2672, 2002.

[15] J. C. King, I. P. Moskowitz, P. G. Burgon et al., "E2F3 plays an essential role in cardiac development and function," Cell Cycle, vol. 7, no. 23, pp. 3775-3780, 2008.

[16] L. M. Julian, R. Vandenbosch, C. A. Pakenham et al., "Opposing regulation of Sox 2 by cell-cycle effectors E2f3a and E2f3b in neural stem cells," Cell Stem Cell, vol. 12, no. 4, pp. 440452, 2013.

[17] B. Rady, Y. Chen, P. Vaca et al., "Overexpression of E2F3 promotes proliferation of functional human $\beta$ cells without induction of apoptosis," Cell Cycle, vol. 12, no. 16, pp. 26912702, 2013.

[18] J. A. Mattison, M. Wang, M. Bernier et al., "Resveratrol prevents high fat/sucrose diet-induced central arterial wall inflammation and stiffening in nonhuman primates," Cell Metabolism, vol. 20, no. 1, pp. 183-190, 2014.

[19] S. J. Park, F. Ahmad, A. Philp et al., "Resveratrol ameliorates aging-related metabolic phenotypes by inhibiting cAMP phosphodiesterases," Cell, vol. 148, no. 3, pp. 421433, 2012.

[20] J. L. Major, A. Dewan, M. Salih, J. J. Leddy, and B. S. Tuana, "E2F6 impairs glycolysis and activates $\mathrm{BDH} 1$ expression prior to dilated cardiomyopathy," PLoS One, vol. 12, no. 1, article e0170066, 2017. 
[21] S. Hille, F. Dierck, C. Kühl et al., "Dyrk1a regulates the cardiomyocyte cell cycle via D-cyclin-dependent Rb/E2f-signalling," Cardiovascular Research, vol. 110, no. 3, pp. 381-394, 2016.

[22] M. Wu, J. Zhou, M. Cheng et al., "E2F1 suppresses cardiac neovascularization by down-regulating VEGF and PlGF expression," Cardiovascular Research, vol. 104, no. 3, pp. 412-422, 2014.

[23] B. Westendorp, J. L. Major, M. Nader, M. Salih, F. H. Leenen, and B. S. Tuana, "The E2F6 repressor activates gene expression in myocardium resulting in dilated cardiomyopathy," The FASEB Journal, vol. 26, no. 6, pp. 2569-2579, 2012.

[24] D. Dingar, F. Konecny, J. Zou, X. Sun, and R. von Harsdorf, "Anti-apoptotic function of the E2F transcription factor 4 $(\mathrm{E} 2 \mathrm{~F} 4) / \mathrm{p} 130$, a member of retinoblastoma gene family in cardiac myocytes," Journal of Molecular and Cellular Cardiology, vol. 53, no. 6, pp. 820-828, 2012.

[25] M. J. van Amerongen, F. Diehl, T. Novoyatleva, C. Patra, and F. B. Engel, "E2F4 is required for cardiomyocyte proliferation," Cardiovascular Research, vol. 86, no. 1, pp. 92-102, 2010.

[26] J. Zhou, Y. Zhu, M. Cheng et al., "Regulation of vascular contractility and blood pressure by the E2F2 transcription factor," Circulation, vol. 120, no. 13, pp. 1213-1221, 2009.

[27] R. Kishore, C. Luedemann, E. Bord, D. Goukassian, and D. W. Losordo, "Tumor necrosis factor-mediated E2F1 suppression in endothelial cells: differential requirement of c-Jun $\mathrm{N}$ terminal kinase and p38 mitogen-activated protein kinase signal transduction pathways," Circulation Research, vol. 93, no. 10, pp. 932-940, 2003.

[28] P. H. Giangrande, J. Zhang, A. Tanner et al., "Distinct roles of E2F proteins in vascular smooth muscle cell proliferation and intimal hyperplasia," Proceedings of the National Academy of Sciences of the United States of America, vol. 104, no. 32, pp. 12988-12993, 2007.

[29] N. Fujita, Y. Furukawa, N. Itabashi, K. Okada, T. Saito, and $\mathrm{S}$. Ishibashi, "Differences in E2F subunit expression in quiescent and proliferating vascular smooth muscle cells," American Journal of Physiology Heart and Circulatory Physiology, vol. 283, no. 1, pp. H204-H212, 2002.

[30] H. Ebelt, N. Hufnagel, P. Neuhaus et al., "Divergent siblings: E2F2 and E2F4 but not E2F1 and E2F3 induce DNA synthesis in cardiomyocytes without activation of apoptosis," Circulation Research, vol. 96, no. 5, pp. 509-517, 2005.

[31] M. Artwohl, K. Muth, K. Kosulin et al., "R-(+)-alpha-lipoic acid inhibits endothelial cell apoptosis and proliferation: involvement of Akt and retinoblastoma protein/E2F-1," American Journal of Physiology Endocrinology and Metabolism, vol. 293, no. 3, pp. E681-E689, 2007.

[32] N. Fujita, Y. Furukawa, J. du et al., "Hyperglycemia enhances VSMC proliferation with NF-kappaB activation by angiotensin II and E2F-1 augmentation by growth factors," Molecular and Cellular Endocrinology, vol. 192, no. 1-2, pp. 75-84, 2002.

[33] M. Jang, L. Cai, G. O. Udeani et al., "Cancer chemopreventive activity of resveratrol, a natural product derived from grapes," Science, vol. 275, no. 5297, pp. 218-220, 1997.

[34] Z. Ungvari, N. Labinskyy, P. Mukhopadhyay et al., "Resveratrol attenuates mitochondrial oxidative stress in coronary arterial endothelial cells," American Journal of Physiology Heart and Circulatory Physiology, vol. 297, no. 5, pp. H1876H1881, 2009.

[35] B. B. Kakoti, D. G. Hernandez-Ontiveros, M. S. Kataki, K. Shah, Y. Pathak, and S. K. Panguluri, "Resveratrol and Omega-3 Fatty
Acid: Its Implications in Cardiovascular Diseases," Frontiers in Cardiovascular Medicine, vol. 2, p. 38, 2015.

[36] K. Liu, R. Zhou, B. Wang, and M. T. Mi, "Effect of resveratrol on glucose control and insulin sensitivity: a meta-analysis of 11 randomized controlled trials," The American Journal of Clinical Nutrition, vol. 99, no. 6, pp. 1510-1519, 2014.

[37] J. L. Bitterman and J. H. Chung, "Metabolic effects of resveratrol: addressing the controversies," Cellular and Molecular Life Sciences, vol. 72, no. 8, pp. 1473-1488, 2015. 